\title{
Faktor-Faktor Yang Mempengaruhi Persepsi Masyarakat Muslim Terhadap Zakat Sebagai Pengurang Pajak
}

\author{
Slamet Wahyuni ${ }^{1}$ Muhammad Saddam ${ }^{2} \&$ Syahril Djaddang ${ }^{3}$ \\ ${ }^{123}$ Sekolah Tinggi Ilmu Ekonomi Hidayatullah, Depok, Indonesia \\ Email : syahril.djaddang@stiehidayatullah.ac.id
}

\begin{abstract}
The aim of this study is to explore the factors that influence the perception of the Muslim community on tax reduction through zakat in Indonesia. This research was conducted on taxpayers registered at KPP Pratama Depok City, by taking samples directly in the field, using a questionnaire as a data collection tool. This study found that the halal-haram aspects of Islamic Sharia had no influence on the Muslim community's perception of the taxable income reduction system through zakat. In addition, religiosity does not have a significant positive impact on the perception of the Muslim community towards this system. This research offers unique findings that can help in leveraging practices in Muslim countries and to understand their people's perceptions of the tax reduction system.
\end{abstract}

Keywords: Perception, Muslim community, taxable income, religiosity, zakat, tax deduction

\begin{abstract}
ABSTRAK
Tujuan dari penelitian ini adalah untuk mengeksplorasi faktor-faktor yang mempengaruhi persepsi masyarakat Muslim terhadap pengurangan pajak melalui zakat di Indonesia. Penelitian ini dilakukan terhadap wajib pajak yang terdaftar pada KPP Pratama Kota Depok, dengan mengambil sample secara langsung di lapangan, dengan penggunaan kuesioner sebagai alat pendataan. Penelitian ini menemukan bahwa aspek halal-haram dari Syariah Islam tidak memiliki pengaruh pada persepsi masyarakat Muslim terhadap sistem pengurangan penghasilan kena pajak melalui zakat. Selain itu, religiusitas tidak memiliki dampak positif yang signifikan terhadap persepsi masyarakat Muslim terhadap sistem ini. penelitian ini menawarkan temuan unik yang dapat membantu dalam memanfaatkan praktik di negara-negara Muslim dan untuk memahami persepsi masyarakat mereka mengenai sistem pengurangan pajak.
\end{abstract}

Kata kunci: Persepsi, masyarakat Muslim, penghasilan kena pajak, religiusitas, zakat

\section{PENDAHULUAN}

Tujuan zakat dapat dikatakan tidak jauh berbeda dari tujuan perpajakan. Perpajakan dan zakat memiliki perbedaan pada sumber yuridiksi, pondasi hipotesis, tujuan, tarif, dan alokasi peruntukan (Abu Bakar \& Rashid, 2010). Walaupun demikian zakat dalam fungsinya adalah "pajak" dalam agama Islam yang dibebankan pada anggota masyarakat kaya untuk dibagikan kepada orang miskin dan orang yang membutuhkan serta penerima lain berdasarkan tolok ukur menurut Al-Qur'an. Zakat memiliki fungsi untuk mempertahankan kemakmuran sosial ekonomi orang miskin dan yang membutuhkan (Al-Mamun et al., 2019).

(Fauzia, 2013) dalam (Adib, 2017) mengungkapkan bahwa terdapat lima model pengelolaan zakat di era kontemporer ini, yaitu pertama, dikumpulkan dan dikelola oleh

\section{JIAKES}

Jurnal Ilmiah Akuntansi Kesatuan Vol. 9 No. 1, 2021 pg. 179-184 IBI Kesatuan ISSN $2337-7852$ E-ISSN 2721 - 3048 
Zakat, Muslim

Perception and

Tax Deduction

$\underline{180}$ negara dengan konsekuensi adanya kewajiban; kedua, dikelola oleh swasta dan diatur kewajibannya dalam peraturan; ketiga, dikelola secara sukarela oleh negara; keempat, dikelola secara sukarela oleh swasta; kelima, dikelola dengan sukarela secara individual.

Di Indonesia zakat dikelola oleh negara dan swasta, metode pengelolaan campuran ini tertuang dalam UU Nomor 23 tahun 2011 tentang Pengelolaan Zakat, dimana negara memiliki andil pengelolaan melalui BAZNAS dibantu oleh Lembaga swasta atau LAZ yang telah eksis terlebih dahulu. Selain itu Undang-undang tersebut juga mengatur tentang insentif pajak bagi masyarakat Muslim yang membayar zakat, dimana zakat yang dibayarkan oleh wajib pajak dapat mengurangi penghasilan kena pajak. insentif ini diberikan agar wajib pajak tidak terkena kewajiban atau beban ganda.

Peraturan tersebut selain dibuat untuk meningkatkan gairah Muslim dalam membayar zakat melalui lembaga resmi juga dibuat untuk meningkatkan kepatuhan wajib pajak muslim dalam memenuhi kewajiban perpajakannya. Hal ini dapat dilihat dari potensi zakat sebesar 217 Triliun namun baru 1\% yang berhasil dihimpun dari potensi yang ada (Rulian et al., 2015). Demikian juga rasio pajak Indonesia yang rendah dimana pada tahun 2017, Indonesia menduduki peringkat terbawah tax ratio disbanding negara-negara Asia Pasifik (OECD, 2019).

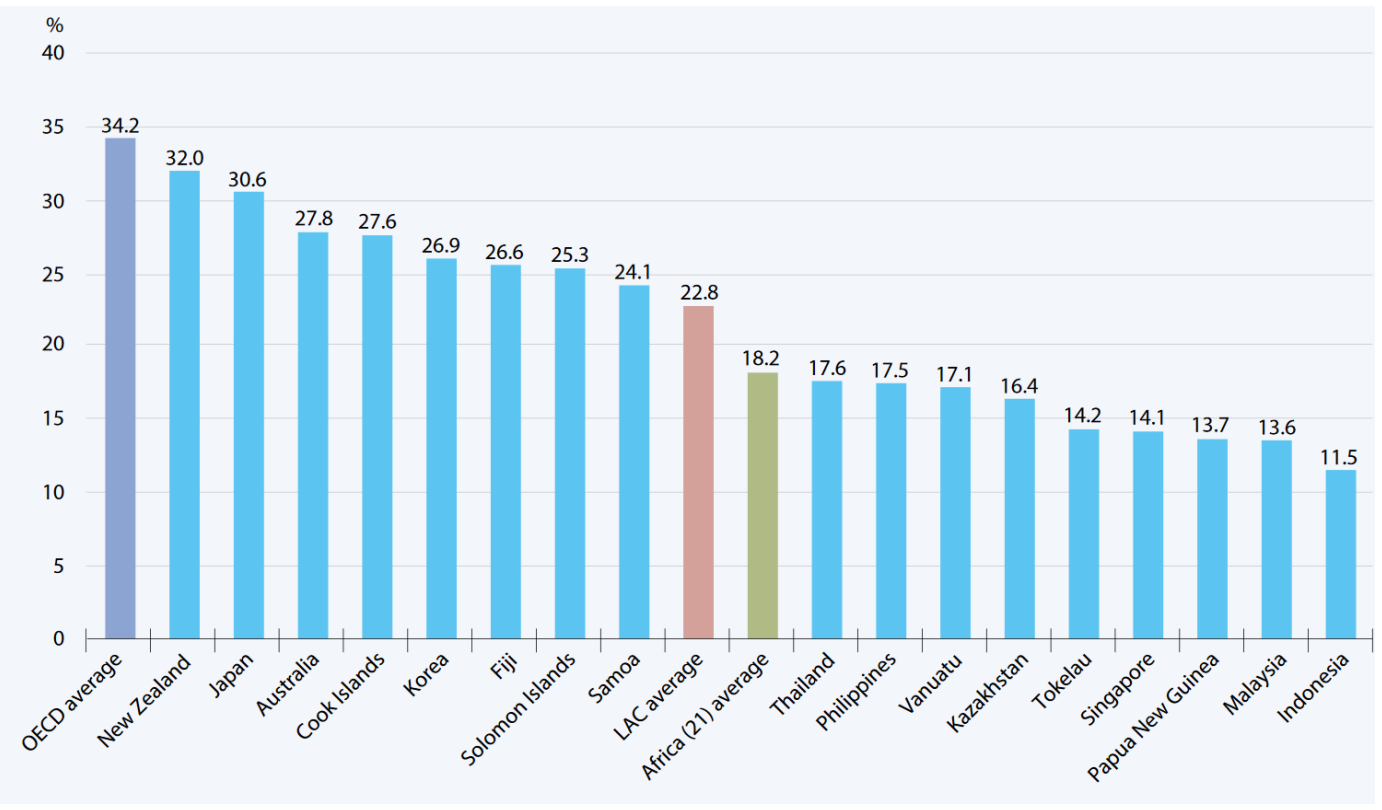

Gambar 1 Tax ratio Negara-negara Asia Pasifik

Dengan adanya dorongan pemerintah terhadap zakat serta adanya zakat sebagai insentif pajak, performa penerimaan zakat dan pajak seharusnya menjadi lebih baik.

Teori Stewardship menjelaskan mengenai situasi dimana manajemen tidaklah hanya termotivasi oleh tujuan-tujuan individu, melainkan lebih ditujukan pada sasaran utama mereka untuk kepentingan organisasi (Donaldson \& Davis, 1991). Teori ini menggambarkan tentang adanya hubungan yang kuat antara kepuasan individu dan kesuksesan organisasi. Dalam hal ini pemerintah dan Lembaga amil zakat selaku steward sebagai pengelola sumber daya dan rakyat selaku principal sebagai pemilik sumber daya. Terjadi kesepakatan yang terjalin antara pemerintah dan Lembaga amil (steward) dan rakyat (principal) berdasarkan kepercayaan untuk mencapai tujuan organisasi. Pemerintah akan berusaha semaksimal mungkin dalam menjalankan pemerintahan untuk mencapai tujuan pemerintah dan Lembaga amil yaitu meningkatkan kesejahteraan rakyat.

Persepsi oleh (Schifmann, L.G. Kanuk, 2008) sebagai suatu proses dimana seseorang memilih, mengatur, dan menjelaskan rangsangan sensorik untuk menjadi lebih baik memahami dunia. Proses persepsi membantu kita untuk memahami orang lain; mengapa mereka memiliki ide atau kepercayaan yang berbeda dan mengapa mereka ingin ketat pada posisi atau membatasi sistem kepercayaan mereka; dan juga membantu kita untuk 
memghormati kepentingan orang lain dalam hal yang sama penting untuk menghindari konflik (Bokeno, 2011). Persepsi penerima zakat dan manajemen lembaga zakat sangat penting karena mereka adalah pengguna akhir dari layanan zakat dan manajemen ialah pihak yang mengimplementasikan pelayanan yang tepat untuk terwujudnya kinerja yang baik (Wahid, 2011)

Agama sangat penting bagi setiap individu dan dianggap sebagai pilar permanen yang ada dalam kehidupan orang percaya selamanya. Agama adalah salah satu aspek yang paling nyata dalam masyarakat yang memotivasi setiap aspek gaya hidup seseorang, kepercayaan, sikap dan juga perilaku (Hanzaee et al., 2011). (Torgler, 2006) membahas bahwa religiusitas adalah aspek penting yang mempengaruhi moral pajak, yang diriwayatkan sebagai motivasi intrinsik untuk membayar pajak. Penulis yang digunakan berbagai ukuran seperti kehadiran gereja, pendidikan agama, peserta aktif sebuah gereja atau lembaga keagamaan, persepsi religiusitas, pengawasan agama dan percaya pada gereja. (Muslichah, 2015) menyebutkan bahwa Semakin tinggi derajat religiusitas, semakin kuat efek penyederhanaan pajak pada perilaku kepatuhan. Religiusitas sangat penting karena menentukan kognisi dan perilaku individu. Agama adalah pengaruh kuat pada perilaku manusia dan penelitian sebelumnya telah mengidentifikasi berbagai faktor yang terkait dengan agama yang pada akhirnya dapat mempengaruhi perilaku.

Halal berasal dari kata Arab yang menunjukkan hal-hal yang dapat diterima dalam Islam dan diizinkan oleh hukum Islam, Dalam Islam, sangat penting untuk menjaga halal dan menjauhkan diri dari haram setiap aspek kehidupan (Wilson, 2014). Wilson, 2014 juga menyatakan bahwa hati nurani dan akuntabilitas manusia dapat menjadi area penting di mana halal dapat memainkan peran penting. Karena itu, penting untuk mengkonfirmasi status produk apakah produknya halal atau haram. Masalah halal dan haram sangat penting bagi umat Islam, karena berkaitan dengan klaim agama. Karena itu, memberlakukan hukum apa pun atau peraturan tentang halal atau masalah haram dari umat Islam perlu diperhitungkan (Halim et al., 2014)

\section{METODE PENELITIAN}

Untuk mencapai tujuan penelitian, penelitian ini difokuskan pada data primer yang telah dikumpulkan di KPP Pratama Kota Depok dengan menggunakan kuesioner tertutup. Riset menggunakan skala Likert. Model regresi yang digunakan dalam penelitian ini adalah regresi linear.

Variabel dependen penelitian ini yaitu persepsi tentang zakat sebagai pengurang pajak yang diproksikan dengan pertanyaan-pertanyaan berikut:

1. Saya merasa dapat menerima dan dengan senang hati perihal pemotongan pajak melalui zakat

2. Cara membayar zakat dan mendapatkan potongan pajak dari pembayaran tersebut dapat dimengerti

3. Saya percaya insentif zakat sebagai pemotong pajak dapat memotivasi Muslim untuk membayar zakat dan pajak mereka.

Terdapat dua variabel Independen dalam penelitian ini yaitu :Varibel pertama adalah religiusitas yang diproksikan dengan pertanyaan-pertanyaan berikut:

a. Ketaatan saya kepada agama mempengaruhi saya untuk patuh membayar zakat dan pajak

b. Saya memotivasi orang lain untuk menggunakan zakat sebagai potongan pajak agar tidak terjadi double taxation

c. Buku dan informasi mengenai keagamaan saya mempengaruhi saya untuk menggunakan zakat sebagai pemotong pajak

Variabel keduanya adalah Halal Haram yang diproksikan dengan pertanyaan-pertanyaan berikut:

a. Saya sangat taat terhadap halal dan haram dalam Islam

b. Saya bertanya kepada ahlinya terkait dengan status halal dan haram suatu transaksi 
Zakat, Muslim Perception and Tax Deduction

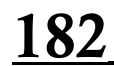

c. Saya yakin zakat sebagai potongan pajak diijinkan atau halal menurut agama saya

\section{HASIL DAN PEMBAHASAN}

Data yang disajikan dalam penelitian ini merupakan data primer yang berasal dari wajib pajak muslim yang terdaftar pada KPP Pratama Kota Depok. Objek penelitian yang digunakan dalam penelitian ini kuesioner yang diisi oleh 30 responden.

\section{Hasil Uji Kualitas Data}

Tabel 1 Hasil Uji Validitas Variabel Persepsi Masyarakat Muslim

\begin{tabular}{|c|c|c|c|c|c|}
\hline & Keterangan & $\mathrm{x} 1.1$ & $\mathrm{x} 1.2$ & $\mathrm{x} 1.3$ & $\mathrm{X} 1$ total \\
\hline \multirow[t]{3}{*}{$\mathrm{x} 1.1$} & Pearson Correlation & 1 & .071 & -.134 & $.552^{* \star}$ \\
\hline & Sig. (2-tailed) & & .708 & .481 & .002 \\
\hline & $\mathrm{N}$ & 30 & 30 & 30 & 30 \\
\hline \multirow[t]{3}{*}{$\mathrm{x} 1.2$} & Pearson Correlation & .071 & 1 & .000 & $.631^{* *}$ \\
\hline & Sig. (2-tailed) & .708 & & 1.000 & .000 \\
\hline & $\mathrm{N}$ & 30 & 30 & 30 & 30 \\
\hline \multirow[t]{3}{*}{$\mathrm{x} 1.3$} & Pearson Correlation & -.134 & .000 & 1 & $.512^{* *}$ \\
\hline & Sig. (2-tailed) & .481 & 1.000 & & .004 \\
\hline & $\mathrm{N}$ & 30 & 30 & 30 & 30 \\
\hline \multirow[t]{3}{*}{ X1total } & Pearson Correlation & $.552^{* *}$ & $.631^{* *}$ & $.512^{* *}$ & 1 \\
\hline & Sig. (2-tailed) & .002 & .000 & .004 & \\
\hline & $\mathrm{N}$ & 30 & 30 & 30 & 30 \\
\hline
\end{tabular}

**. Correlation is significant at the 0.01 level (2-tailed).

Tabel 1 menunjukkan bahwa variabel persepsi masyarakat muslim memiliki indikator yang berkorelasi kuat terhadap variabel induknya. Variabel Religiulitas pun demikian, seluruh indicatornya berkorelasi kuat terhadap variabel induknya. (Lihat Tabel 2). Pada tabel 3 ditampilkan nilai korelasi indikator-indikator variabel halal-haram yang menunjukkan adanya hubungan kuat indikator tersebut dengan variabel induknya. Sehingga berdasarkan ketiga tabel tersebut, seluruh variabel telah memenuhi syarat validitas dan dapat dilanjutkan pada analisis berikutnya menggunakan metode analisis regresi berganda. Hasil uji reliabilitas data, ditampilkan pada Tabel 4 yang menunjukkan bahwa seluruh variabel telah memenuhi syarat kehandalan yang dibuktikan dengan nilai cronbach's alpha 0,650 yang melebihi nilai 0,6 . Dengan nilai tersebut, seluruh variabel telah memenuhi persyaratan untuk dilakukan uji selanjutnya.

Tabel 2 Hasil Uji Validitas Variabel Religiulitas

\begin{tabular}{lll|l|l|l}
\multicolumn{2}{l}{ Keterangan } & $\mathrm{x} 2.1$ & $\mathrm{x} 2.2$ & $\mathrm{x} 2.3$ & $\mathrm{x} 2$ total \\
\hline $\mathrm{x} 2.1$ & Pearson Correlation & 1 & -.218 & -.056 & $.465^{* *}$ \\
\cline { 2 - 6 } & Sig. (2-tailed) & & .247 & .767 & .010 \\
\cline { 2 - 6 } & $\mathrm{N}$ & 30 & 30 & 30 & 30 \\
\hline $\mathrm{x} 2.2$ & Pearson Correlation & -.218 & 1 & -.018 & $.503^{* *}$ \\
\cline { 2 - 6 } & Sig. (2-tailed) & .247 & & .923 & .005 \\
\cline { 2 - 6 } & $\mathrm{N}$ & 30 & 30 & 30 & 30 \\
\hline x2.3 & Pearson Correlation & -.056 & -.018 & 1 & $.585^{* *}$ \\
\cline { 2 - 6 } & Sig. (2-tailed) & .767 & .923 & & .001 \\
\cline { 2 - 6 } & $\mathrm{N}$ & 30 & 30 & 30 & 30 \\
\hline x2total & Pearson Correlation & $.465^{* *}$ & $.503^{* *}$ & $.585^{* *}$ & 1 \\
\cline { 2 - 6 } & Sig. (2-tailed) & .010 & .005 & .001 & \\
\cline { 2 - 6 } & $\mathrm{N}$ & 30 & 30 & 30 & 30 \\
\hline
\end{tabular}

**. Correlation is significant at the 0.01 level (2-tailed). 
Tabel 3 Hasil Uji Validitas Variabel Halal-Haram

\begin{tabular}{cl|l|l|l|l}
\multicolumn{2}{l}{ Keterangan } & $\mathrm{y} 1.1$ & $\mathrm{y} 1.2$ & $\mathrm{y} 1.3$ & Ytotal \\
\hline \multirow{2}{*}{ y1.1 } & Pearson Correlation & 1 & -.189 & .236 & $.589^{* *}$ \\
\cline { 2 - 6 } & Sig. (2-tailed) & & .317 & .209 & .001 \\
\cline { 2 - 6 } y1.2 & $\mathrm{N}$ & 30 & 30 & 30 & 30 \\
\cline { 2 - 6 } & Pearson Correlation & -.189 & 1 & -.071 & $.445^{*}$ \\
\cline { 2 - 6 } & Sig. (2-tailed) & .317 & & .708 & .014 \\
\hline y1.3 & Pearson Correlation & 30 & 30 & 30 & 30 \\
\cline { 2 - 6 } & Sig. (2-tailed) & .236 & -.071 & 1 & $.684^{* *}$ \\
\cline { 2 - 6 } & $\mathrm{N}$ & 30 & .708 & & .000 \\
\hline Ytotal & Pearson Correlation & $.589^{* *}$ & $.445^{*}$ & $.684^{* *}$ & 1 \\
\cline { 2 - 6 } & Sig. (2-tailed) & .001 & .014 & .000 & \\
\cline { 2 - 6 } & $\mathrm{N}$ & 30 & 30 & 30 & 30 \\
\hline
\end{tabular}

**. Correlation is significant at the 0.01 level (2-tailed).

*. Correlation is significant at the 0.05 level (2-tailed).

Tabel 4 Hasil Uji Reliabilitas

Cronbach's Alpha N of Items

\begin{tabular}{l|l}
\hline .652 & 4 \\
\hline
\end{tabular}

Tabel 5 Hasil Uji Normalitas

\begin{tabular}{ll|l|l|l|l|l}
\multicolumn{3}{c}{ Kolmogorov-Smirnov } & \multicolumn{2}{l}{ Shapiro-Wilk } \\
& Statistic & Df & Sig. & Statistic & df & Sig. \\
\hline ytotal & .259 & 30 & .000 & .863 & 30 & .001 \\
\hline
\end{tabular}

a. Lilliefors Significance Correction

Hasil Uji Regresi

Tabel 6 Hasil Uji Regresi

\begin{tabular}{cc|c|c|c|c} 
Model & $\mathrm{R}$ & R Square & Adjusted R Square & Std. Error of the Estimate & $\mathrm{F}$ \\
\hline 1 & $.189^{\mathrm{a}}$ & .036 & -.036 & .87016 & .612 \\
\hline
\end{tabular}

\section{Pembahasan}

Berdasarkan pengujian di atas, dapat dilihat bahwa religiusitas tidak berpengaruh positif dan signifikan terhadap persepsi zakat sebagai pengurang pajak. Hasil ini tidak sesuai dengan hipotesis yang diajukan dan berbeda dengan penelitian yang dilakukan oleh (Al-Mamun \& Haque, 2015) yang menyatakan bahwa religiusitas memiliki pengaruh yang positif dan siginifikan terhadap persepsi zakat sebagai pengurang pajak.

Berikutnya adalah Aspek Halal dan Haram, menurut pengujian diatas dapat dilihat bahwa Halal dan Haram tidak memiliki pengaruh yang positifi dan signifikan terhadap persepsi zakat sebagai pengurang pajak. hasil uji tersebut berbeda dengan penelitian yang dilakukan oleh (Al-Mamun et al., 2019) yang menyatakan bahwa Aspek Halal dan Haram memiliki pengaruh positif dan signifikan terhadap persepsi zakat sebagai pengurang pajak.

\section{PENUTUP}

Berdasarkan hasil penelitian dapat disimpulkan bahwa di Indonesia yang notabene nya penduduk Muslim terbesar di dunia, religiusitas dan Halal Haram tidak memiliki pengaruh terhadap persepsi zakat sebagai pengurang pajak. Dalam penelitian ini tentunya masih memiliki keterbatasan diantaranya adalah jumlah responden yang sangat sedikit dan alat uji yang digunakan tidak sama dengan penelitian-penelitian sebelumnya. Sebagai implikasi dari penelitian ini maka saran yang dapat diberikan oleh peneiliti 
Zakat, Muslim Perception and Tax Deduction

184 adalah 1). Penelitian selanjutnya diharapkan menambahkan jumlah responden, 2). Alat uji disarankan menggunakan SEM, 3). Menjadikan variable Halal Haram sebagai varibel pemoderasi dan menambahkan proksi setiap variable.

\section{DAFTAR PUSTAKA}

Abu Bakar, N. B., \& Rashid, H. M. A. (2010). Motivations of Paying Zakat on Income: Evidence from Malaysia. International Journal of Economics and Finance, 2(3), 76-84. https://doi.org/10.5539/ijef.v2n3p76

Adib, C. (2017). Peran Negara Dalam Pengelolaan Zakat Umat Islam Di Indonesia. Jurnal Nestor Magister Hukum, 28.

Al-Mamun, A., Haque, A., \& Jan, M. T. (2019). Measuring perceptions of Muslim consumers toward income tax rebate over zakat on income in Malaysia. Journal of Islamic Marketing. https://doi.org/10.1108/JIMA-12-2016-0104

Al-Mamun, A., \& Haque, A. K. M. A. (2015). Perception of muslim consumers towards tax deduction through Zakat in malaysia: an empirical investigation on muslims in Malaysia. Conference on Shari'ah Oriented Public Policy in Islamic Economic System, March, 532-549. http://irep.iium.edu.my/46767/

Bokeno, R. M. (2011). Learning in conflict: Revisiting the role of perception. Development and Learning in Organisations, 25(2), 15-17. https://doi.org/10.1108/14777281111108227

Donaldson, L., \& Davis, J. H. (1991). Stewardship Theory or Agency Theory: CEO Governance and Shareholder Returns. Australian Journal of Management, 16(1), 4964. https://doi.org/10.1177/031289629101600103

Fauzia, A. (2013). Faith and The State: a History of Islamic Philanthrophy in Indonesia.

Halim, M. 'Afifi bin A., Mohd, K. W. binti, Salleh, M. M. M., Yalawae, A., Omar, T. S. M. N. S., Ahmad, A., Ahmad, A. A. binti, \& Kashim, M. I. A. bin M. (2014). Consumer Protection of Halal Products in Malaysia: A Literature Highlight. Procedia - Social and Behavioral Sciences, 121(September 2012), 68-78. https://doi.org/10.1016/j.sbspro.2014.01.1109

Hanzaee, K. H., Attar, M. M., \& Alikhan, F. (2011). Investigating the effect of gender role attitude on the relationship between dimensions of religiosity and new product adoption intention. In World Applied Sciences Journal (Vol. 13, Issue 6, pp. 15271536).

Muslichah. (2015). The effect of tax simplification on taxpayers' compliance behavior: religiosity as moderating variable. 19(2), 98-108.

OECD. (2019). Revenue Statistics in Asian and Pacific Economies.

Purba, J. H. V., Ratodi, M., Mulyana, M., Wahyoedi, S., Andriana, R., Shankar, K., \& Nguyen, P. T. (2019). Prediction Model in Medical Science and Health Care. International Journal of Engineering and Advanced Technology, 8, 815-818.

Rulian, N. A., Anggraeni, L., \& Lubis, D. (2015). Analisis Faktor-faktor yang Memengaruhi Muzaki dalam Memilih Organisasi Pengelola Zakat (OPZ): Studi Kasus di Badan Amil Zakat Nasional Kota Bogor. Al-Muzara'ah, 3(1), 20-33. https://doi.org/10.29244/jam.3.1.20-33

Schifmann, L.G. Kanuk, H. (2008). Consumer Behaviour: A European Outlook. Prentice Hall.

Torgler, B. (2006). The importance of faith: Tax morale and religiosity. Journal of Economic Behavior and Organization, 61(1), 81-109. https://doi.org/10.1016/j.jebo.2004.10.007

Wahid, H. (2011). Localization of Zakat Distribution and The Role of Mosque: Perceptions of Amil and Zakat Recipents in Malaysia. International Zakat Forum 2011, 1-25. https://doi.org/10.1007/s13398-014-0173-7.2

Wilson, J. A. J. (2014). The $<\mathrm{I}>$ halal $</ \mathrm{I}>$ phenomenon: An extension or a new paradigm? Social Business, 4(3), 255-271. https://doi.org/10.1362/204440814x14103454934294 